\title{
Communication
}

\section{Design of a Novel Wideband Leaf-Shaped Printed Dipole Array Antenna Using a Parasitic Loop for High-Power Jamming Applications}

\author{
Eunjung Kang ${ }^{1}\left(\mathbb{D}\right.$, Tae Heung Lim ${ }^{1, *} \mathbb{(}$, Seulgi Park ${ }^{2}$ and Hosung Choo $^{1} \mathbb{(}$ \\ 1 Department of Electronic and Electrical Engineering, Hongik University, Seoul 04066, Korea; \\ ej0901@mail.hongik.ac.kr (E.K.); hschoo@hongik.ac.kr (H.C.) \\ 2 Hanwha Systems Co., Ltd., Seongnam City 13524, Korea; sg0212.park@hanwha.com \\ * Correspondence: qpzm0105@mail.hongik.ac.kr
}

check for updates

Citation: Kang, E.; Lim, T.H.; Park,

S.; Choo, H. Design of a Novel

Wideband Leaf-Shaped Printed

Dipole Array Antenna Using a

Parasitic Loop for High-Power

Jamming Applications. Sensors 2021,

21, 6882. https://doi.org/

$10.3390 /$ s21206882

Academic Editor: Ángela

María Coves Soler

Received: 21 September 2021

Accepted: 11 October 2021

Published: 17 October 2021

Publisher's Note: MDPI stays neutral with regard to jurisdictional claims in published maps and institutional affiliations.

Copyright: (C) 2021 by the authors. Licensee MDPI, Basel, Switzerland. This article is an open access article distributed under the terms and conditions of the Creative Commons Attribution (CC BY) license (https:// creativecommons.org/licenses/by/ $4.0 /)$.

\begin{abstract}
This paper proposes a novel wideband leaf-shaped printed dipole antenna sensor that uses a parasitic element to improve the impedance matching bandwidth characteristics for highpower jamming applications. The proposed antenna sensor consists of leaf-shaped dipole radiators, matching posts, rectangular slots, and a parasitic loop element. The leaf-shaped dipole radiators are designed with exponential curves to obtain a high directive pattern and are printed on a TLY-5 substrate for high-power durability. The matching posts, rectangular slots, and a parasitic loop element are used to enhance the impedance matching characteristics. The proposed antenna sensor has a measured fractional bandwidth of $66.7 \%$ at a center frequency of $4.5 \mathrm{GHz}$. To confirm the array antenna sensor characteristics, such as its active reflection coefficients (ARCs) and beam steering gains, the proposed single antenna sensor is extended to an $11 \times 1$ uniform linear array. The average values of the simulated and measured ARCs from 4.5 to $6 \mathrm{GHz}$ are $-13.4 \mathrm{~dB}$ and $-14.7 \mathrm{~dB}$. In addition, the measured bore-sight array gains of the co-polarization are $13.4 \mathrm{dBi}$ and $13.7 \mathrm{dBi}$ at $4 \mathrm{GHz}$ and $5 \mathrm{GHz}$, while those of the cross-polarizations are $-4.9 \mathrm{dBi}$ and $-3.4 \mathrm{dBi}$, respectively. When the beam is steered at a steering angle, $\theta_{0}$, of $15^{\circ}$, the maximum measured array gains of the co-polarization are $12.2 \mathrm{dBi}$ and $10.3 \mathrm{dBi}$ at $4 \mathrm{GHz}$ and $5 \mathrm{GHz}$, respectively.
\end{abstract}

Keywords: jammer antenna; printed dipole; wideband antenna; parasitic element

\section{Introduction}

In electronic warfare, high-power jamming systems have been widely used to impede the radio frequency $(\mathrm{RF})$ signal detection of friendly forces by producing interference signals to jam enemy RF radar systems [1]. However, the development of radar design technology has supported such RF radar systems with multifunctional modes to avoid jamming signals by using various frequency bands. Thus, it is essential for high-power jamming applications to also have wideband characteristics in order for antennas to efficiently interfere with RF radar signals with diverse frequencies. Extensive efforts have been devoted to enhancing the frequency bandwidth of antennas by employing various design structures, such as a Vivaldi antenna with a flared-notched shape [2], a folded patch antenna with shorting pins [3], a horn antenna with a substrate-integrated waveguide [4], and double exponentially tapered slot antennas [5,6]. Although these approaches have achieved the wideband characteristics of a single antenna, the physical antenna size is too large to mount on jamming applications with multiple antenna elements. To overcome this problem, many studies have investigated miniaturizing the antenna size by applying a meander line on a log-periodic dipole antenna (LPDA) [7], a hybrid-type antenna with wideband characteristics antennas, i.e., a horn antenna and Vivaldi antenna [8,9], and a printed LPDA on a high dielectric substrate [10]. However, these techniques still encounter the problems of high cost and a complex fabrication process, despite the antenna sensor 
size reduction. In addition, more detailed research is required to improve the array antenna sensor characteristics to enable high-power durability for jamming applications.

In this paper, we propose the design of a novel wideband leaf-shaped printed dipole antenna using a parasitic element to improve the impedance matching bandwidth characteristics for high-power jamming applications. The proposed antenna sensor consists of leaf-shaped dipole radiators, matching posts, rectangular slots, and a parasitic loop element. The leaf-shaped dipole radiators are designed by employing exponential curves to obtain a high directivity, and they are printed on a TLY-5 substrate to enable high-power durability. To enhance the impedance matching characteristics, the matching posts are shorted between the radiators and the ground plate [11], and the rectangular slots are inserted at the edges of the radiators. In addition, the parasitic loop element is added to further improve the matching bandwidth by adjusting the loop structure. To verify the feasibility of the proposed antenna sensor, it is measured to observe the antenna characteristics, such as the reflection coefficient, gain, and efficiency according to the parasitic loop. Moreover, the proposed design is extended to an $11 \times 1$ uniform linear array antenna sensor for high-power jamming applications to examine the array properties, such as the active reflection coefficients (ARCs), array gain, and beam steering performance. The proposed array antenna sensor has ARCs of less than $-10 \mathrm{~dB}$ and the measured array gains according to the beam steering angles are similar to those of the simulations. The results confirm that the proposed array is suitable for the high-power jamming applications.

\section{The Proposed Antenna Design and Performance}

Figure 1 illustrates the geometry of the proposed antenna sensor, which is composed of a radiating part and a parasitic element part. The radiating part has three componentsleaf-shaped dipole radiators, rectangular slots, and matching posts-as shown in Figure 1a. The radiators are designed with inner and outer exponential leaf-shaped curves of $f_{1}(z)$ and $f_{2}(z)$ to obtain the broadband matching characteristics as follows:

$$
\begin{aligned}
& f_{1}(z)=c_{1} e^{r_{i}\left(z-\left(h_{1}-h_{1}\right)\right)}+c_{2}, \\
& f_{2}(z)=c_{3} e^{r_{0}\left(z-\left(h_{1}-h_{2}\right)\right)}+c_{4},
\end{aligned}
$$

where $c_{1}, c_{2}, c_{3}$, and $c_{4}$ are the function coefficients for the exponential curves [12]. The exponent coefficients of $r_{i}$ and $r_{o}$ can determine the high directivity, while the inner and outer slopes of the curves can change the current distributions. For high-power durability, the radiators are printed on a TLY-5 substrate $\left(\varepsilon_{r}=2.2, \tan \delta=0.0009\right.$ from Taconic) with dimensions of $w_{1} \times h_{1} \times t$ (width $\times$ height $\times$ thickness). The melting point and dielectric strength of the substrate are $320 \sim 340^{\circ} \mathrm{C}$ and $106,023 \mathrm{~V} / \mathrm{mm}$, which can endure the highpower applications. The feed line length of $h_{2}$ is connected to the radiator with a $50-\Omega$ transmission line, which is fed by an SMA connector at the $\left(f_{x}, f_{y}\right)$ feeding point. The matching posts are employed and shorted between the lower parts of the radiators and the ground plate. To observe the ground effect, the proposed antenna is simulated by varying the width of the square-shaped ground size; the ground size is determined by $100 \mathrm{~mm} \times$ $100 \mathrm{~mm}$ to have less pattern distortion under some frequencies. The distances of $d_{l}$ and $d_{r}$ from the feeding lines to the posts can be adjusted to enhance the low-end frequency matching. The matching posts can adjust the electrical length at the resonant frequency band when asymmetrically changing $d_{l}$ and $d_{r}$. These can also miniaturize the antenna size through shorting the outer curve of the dipole radiator and the ground $[13,14]$. To enhance the high-end frequency matching, the rectangular slots are etched at the dipole radiator edge, where the number of slots is $N$. Each slot is designed with a width of $s_{w}$ and a length of $s_{l}$, as well as a constant interval of $s_{i}$. The slots are located at a distance of $h_{3}$ to increase the current path for the high-end frequency. To determine the dimension, $N$, and the $h_{3}$ of the slots, we carried out parametric studies according to the slot parameters. For example, when increasing the number and size of the slots, the reactance values decrease in the high-end frequency band over $5 \mathrm{GHz}$, where the slot acts as the capacitive loading 
in the radiators. Thus, $N$ of 12 is determined to improve the impedance matching in the high-end frequency band. Figure $1 \mathrm{~b}$ represents the parasitic element part printed on the opposite side of the printed dipole radiators. The parasitic element is designed as a simple loop-shaped patch with a width of $w_{2}$, a length of $l_{1}$, and a height $l_{2}$ from the ground. The proposed parasitic element structure can achieve broad impedance matching characteristics and size miniaturization. This is because the capacitive and inductive reactance of the indirect electromagnetic (EM) couplings between the radiators and the parasitic loop can be adjusted by changing the parameters of the proposed loop structure.

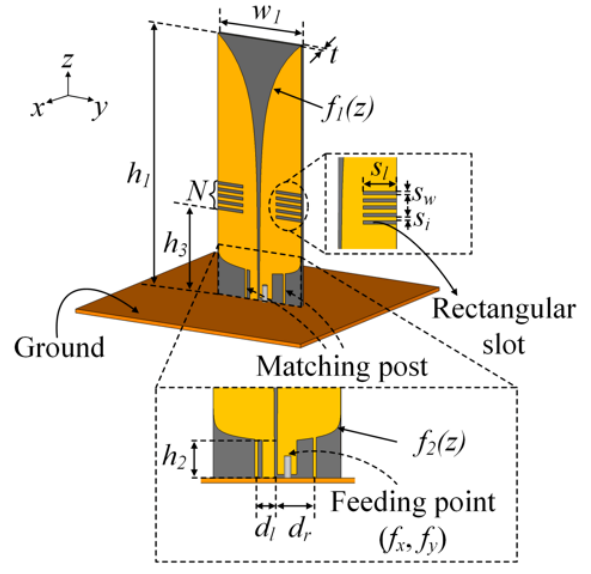

(a)

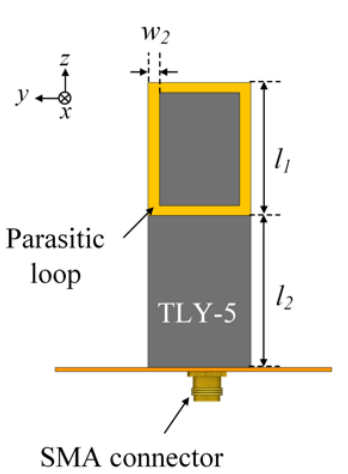

(b)

Figure 1. Geometry of the proposed printed dipole antenna: (a) isometric view; (b) back view.

Figure 2a presents the reflection coefficients in accordance with the existence of the antenna elements (the parasitic loop and slots) to observe the effects on the impedance matching characteristics. We simulated the proposed antenna when each element was removed one by one. The resulting $-10 \mathrm{~dB}$ fractional bandwidths at the center frequency of $4.5 \mathrm{GHz}$ are $66.7 \%$ (the proposed antenna), $41.1 \%$ (without the parasitic loop), $64.4 \%$ (without the slots), and $10.4 \%$ (without the slots and parasitic loop). In particular, the stand-alone dipole with the parasitic element drastically enhances the impedance matching characteristics, meaning that we can further analyze the parametric study for the shape of the parasitic loop. Figure $2 \mathrm{~b}$ illustrates the fractional bandwidth according to the ratio of the parasitic loop thickness and length. The solid and dashed lines indicate the bandwidth results when considering a thickness of $w_{2}$ and a loop length of $l_{1}$. As the loop length, $l_{1}$, increased from $35 \mathrm{~mm}$ to $115.6 \mathrm{~mm}$, the fractional bandwidth was gradually enhanced. The wide fractional bandwidth can be obtained with the narrow width of $0.3 \mathrm{~mm}$ when $w_{2}$ varies from $0.3 \mathrm{~mm}$ to $7 \mathrm{~mm}$. This is because the strong mutual coupling strengths between the radiator and the parasitic loop can adjust the input impedance of the proposed antenna in the low- and high-end frequency band. Thus, the maximum fractional bandwidth of $66.7 \%$ can be obtained when $l_{1}$ is $115.6 \mathrm{~mm}$ and $w_{2}$ is $0.3 \mathrm{~mm}$. Figure $2 \mathrm{c}, \mathrm{d}$ show the reflection coefficients in accordance with the slot height, $h_{3}$, and the number of the slots, $N$. When changing the slot height, $h_{3}$, from $25 \mathrm{~mm}$ to $70 \mathrm{~mm}$, the resonant frequency band became down-shifted. This is because the current path in the radiators can be adjusted by the slot height, which affects the resonant frequency band. In addition, the number and size of the slots can tune the reactance values in the high-end frequency band over $5 \mathrm{GHz}$, where the slot acts as the capacitive loading in the radiators. Through the parametric studies, $N$ of 12 and $h_{3}$ of $40 \mathrm{~mm}$ were determined to improve the impedance matching in the high-end frequency band. The optimized design parameters were obtained using the CST Studio Suite [15], and the detailed values are listed in Table 1. To confirm the feasibility of the proposed antenna sensor, it was fabricated and measured in a full anechoic chamber. 


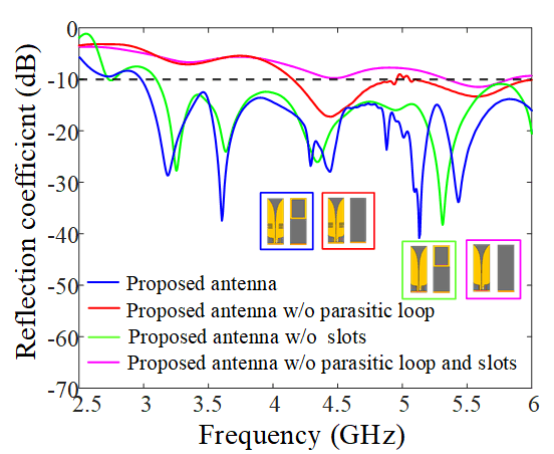

(a)

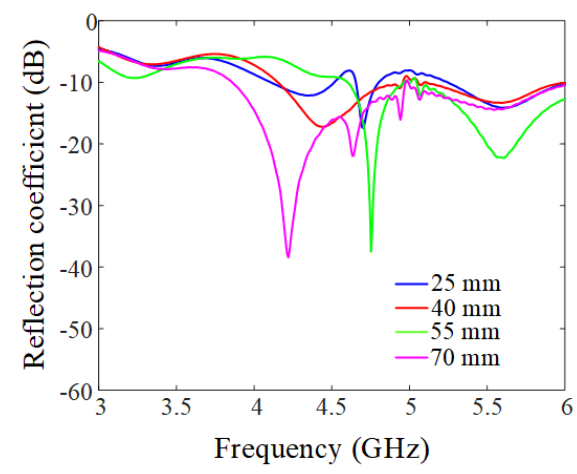

(c)

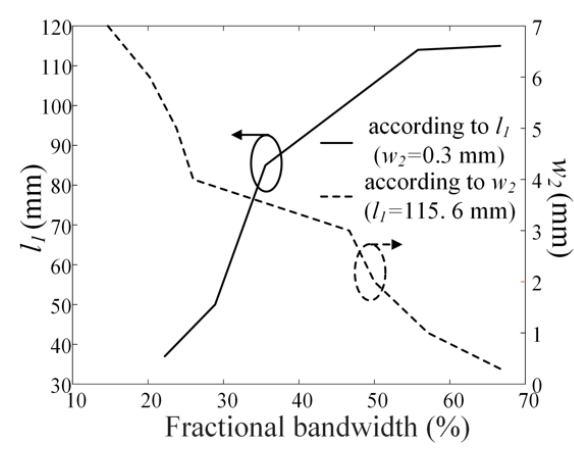

(b)

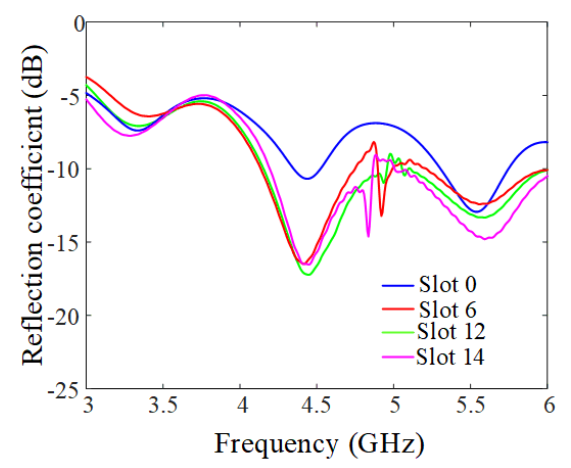

(d)

Figure 2. Parametric studies on the rectangular slots and the parasitic loop: (a) reflection coefficients according to the antenna sensor components; (b) fractional bandwidth according to the parasitic loop structure; (c) reflection coefficients according to $h_{3} ;(\mathbf{d})$ reflection coefficients according to $N$.

Table 1. Values of the proposed antenna.

\begin{tabular}{cccc}
\hline Parameter & Values & Parameter & Values \\
\hline$h_{1}$ & $119 \mathrm{~mm}$ & $l_{1}$ & $115.6 \mathrm{~mm}$ \\
$h_{2}$ & $12 \mathrm{~mm}$ & $l_{2}$ & $3.4 \mathrm{~mm}$ \\
$h_{3}$ & $40 \mathrm{~mm}$ & $d_{r}$ & $30.7 \mathrm{~mm}$ \\
$w_{1}$ & $39.4 \mathrm{~mm}$ & $d_{l}$ & $35.4 \mathrm{~mm}$ \\
$w_{2}$ & $0.3 \mathrm{~mm}$ & $c_{1}$ & -0.025 \\
$r_{i}$ & 0.056 & $c_{2}$ & -39.5 \\
$r_{o}$ & -0.6 & $c_{3}$ & $-5.6 \times 10^{4}$ \\
$s_{1}$ & $12 \mathrm{~mm}$ & $c_{4}$ & -15.9 \\
$s_{w}$ & $0.5 \mathrm{~mm}$ & $t$ & $1.6 \mathrm{~mm}$ \\
$s_{i}$ & $1 \mathrm{~mm}$ & $\left(f_{x}, f_{y}\right)$ & $(0,22.8)$ \\
$N$ & 5 & & \\
\hline
\end{tabular}

Figure 3 shows photographs of the fabricated antenna sensor printed on the TLY-5 substrate for high-power durability; the proposed antenna sensor is directly fed by an SMA connector. Figure 4 presents the measured and simulated reflection coefficients; it can be seen that the results agree well with each other. The maximum values for the measured and simulated reflection coefficients are $-10.1 \mathrm{~dB}$ and $-10.9 \mathrm{~dB}$ from $3 \mathrm{GHz}$ to $6 \mathrm{GHz}$, respectively. The measured fractional matching bandwidth was improved from $55.6 \%$ to $66.7 \%$ when the parasitic loop element was applied. Figure 5 presents the simulated and measured maximum gains of the proposed antenna in the absence and presence of the parasitic loop. The solid and dashed lines indicate the gain results of the simulation with and without the parasitic loop, while " $\mathrm{o}$ " and " $x$ " markers represent those of the measurements. The enhancement of the maximum gain at $3 \mathrm{GHz}$ is $3 \mathrm{~dB}$, because the parasitic loop element can improve the impedance matching characteristic in the low-end 
frequency band. With the parasitic loop element, the improvements of the measured and simulated radiation efficiencies at $3 \mathrm{GHz}$ are $30 \%$ and $40 \%$ due to the enhancement of the matching characteristics in the low-end frequency band. A slight gain discrepancy occurs due to the measurement setup alignments and fabrication errors. Figure 6 shows the simulated and measured radiation patterns of the co- and cross-polarizations in the $z x$ - and $z y$-planes. The measurements agree well with the simulations, and the measured half-power beamwidths in the $z x$-plane are $51.2^{\circ}, 105.2^{\circ}$, and $62^{\circ}$ at $3 \mathrm{GHz}, 4.5 \mathrm{GHz}$, and $6 \mathrm{GHz}$.

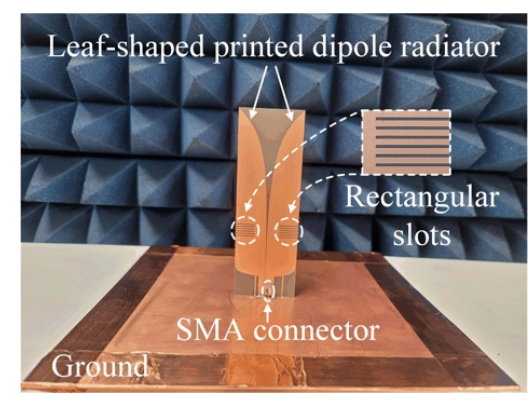

(a)

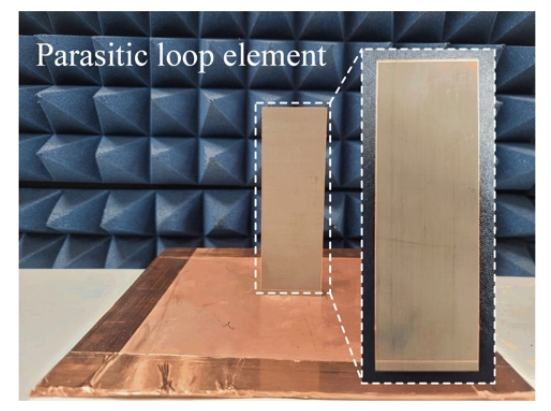

(b)

Figure 3. Photographs of the fabricated antenna sensor: (a) front view; (b) back view.

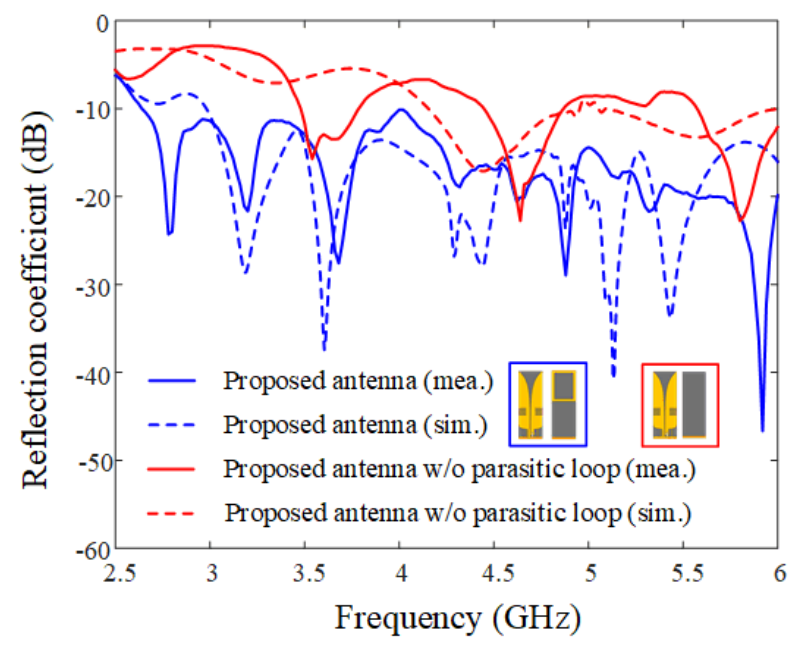

Figure 4. Simulated and measured reflection coefficients of the proposed antenna.

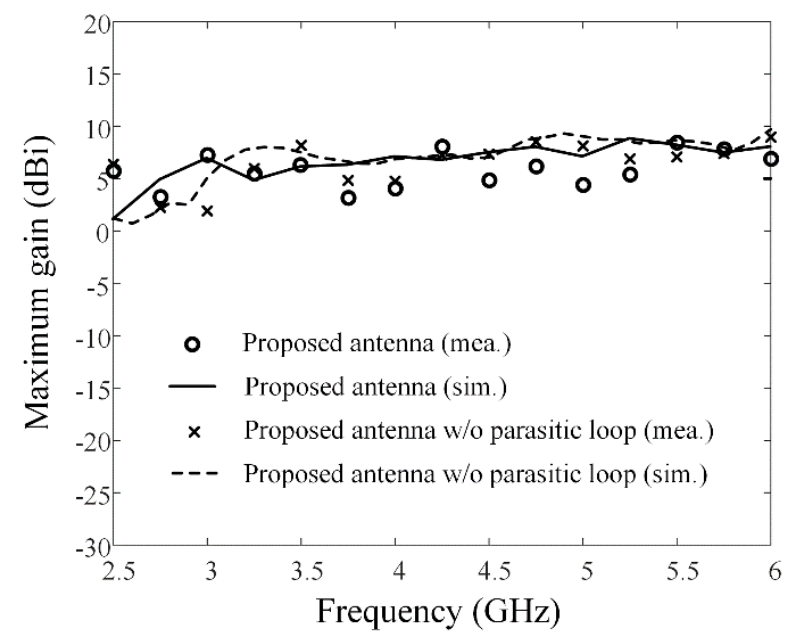

Figure 5. Simulated and measured bore-sight gains of the proposed antenna. 


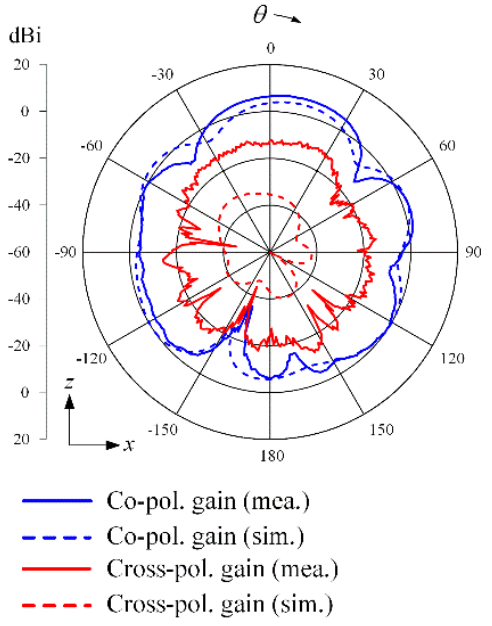

(a)

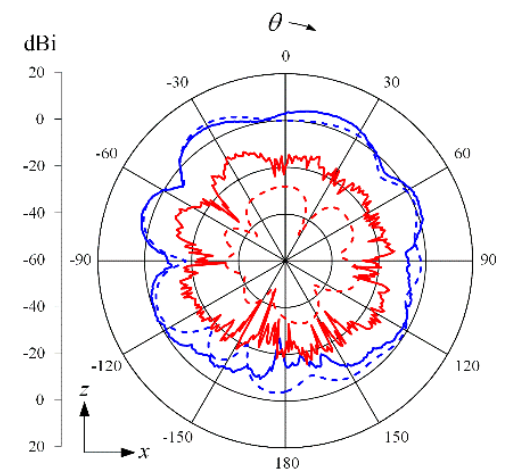

$$
\begin{aligned}
& \text { Co-pol. gain (mea.) } \\
& --- \text { Co-pol. gain (sim.) } \\
& \longrightarrow \text { Cross-pol. gain (mea.) }
\end{aligned}
$$$$
\text { - - - Cross-pol. gain (sim.) }
$$

(c)

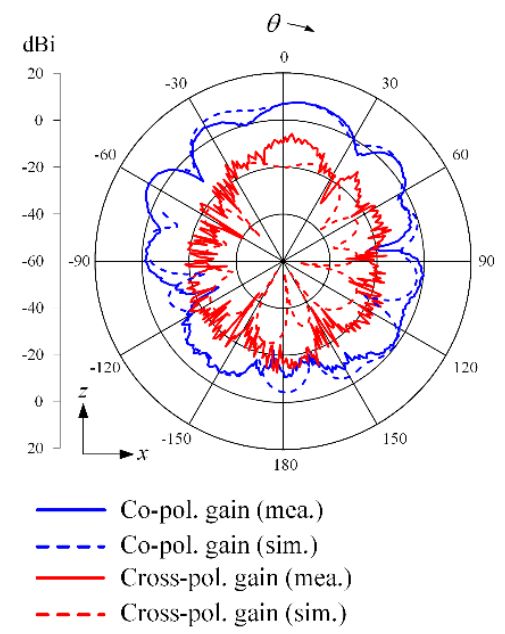

(e)
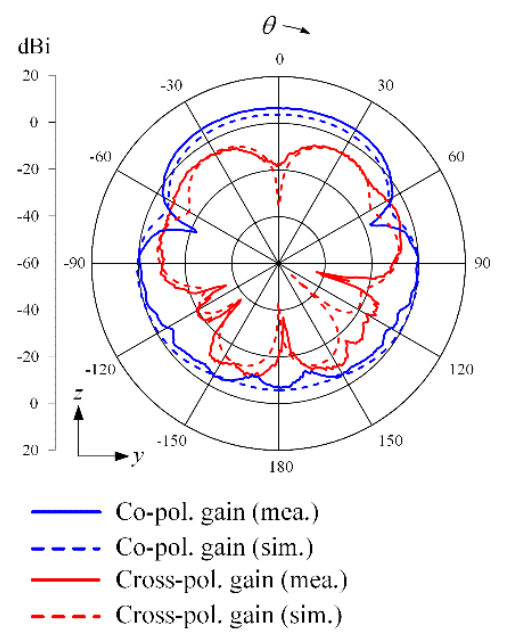

(b)

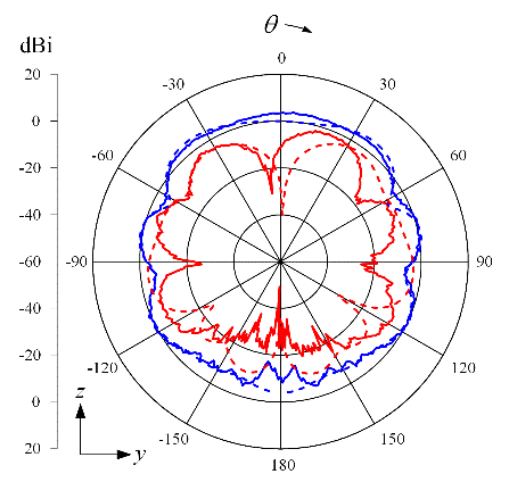

$$
\begin{array}{ll}
- & \text { Co-pol. gain (mea.) } \\
---- & \text { Co-pol. gain (sim.) } \\
- & \text { Cross-pol. gain (mea.) } \\
---- & \text { Cross-pol. gain (sim.) }
\end{array}
$$

(d)
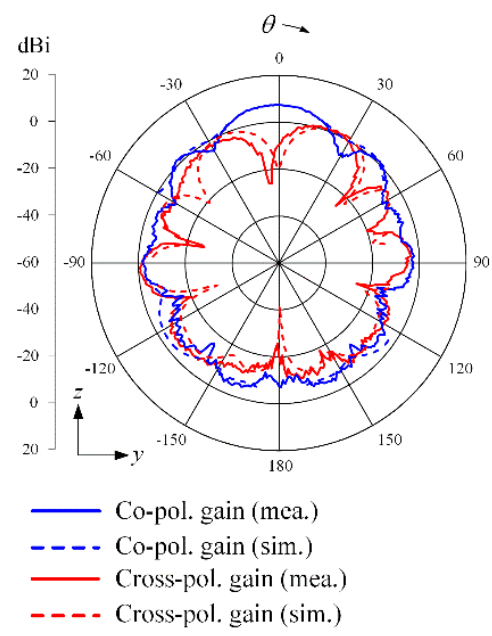

(f)

Figure 6. 2D radiation patterns: (a) $z x$-plane at $3 \mathrm{GHz}$; (b) $z y$-plane at $3 \mathrm{GHz}$; (c) $z x$-plane at $4.5 \mathrm{GHz}$; (d) $z y$-plane at $4.5 \mathrm{GHz}$; (e) $z x$-plane at $6 \mathrm{GHz}$; (f) zy-plane at $6 \mathrm{GHz}$. 


\section{Array Extension and Performance}

To examine the array performance for high-power jamming applications, the proposed array element was re-optimized based on the stand-alone antenna in Chapter 2, where a linear periodic structure was used to account for the mutual couplings between the adjacent elements. Note that the width, $w_{1}$, of the array element (the same as the array distance) is determined by considering the grating lobe that appears when steering the beam. Herein, we used the odd number, 11, of the array element for the finite array to compare the antenna characteristics of the infinite array as similarly as possible. This was because the odd number could define the exact center element of the finite array. The optimized parameter values of the array element are listed in Table 2. Figure $7 \mathrm{a}, \mathrm{b}$ show the fabricated $11 \times 1$ uniform linear array antenna sensor used to confirm the array antenna sensor characteristics. Figure $7 \mathrm{c}$ presents a photograph of the measurement setup in a full anechoic chamber. In this setup, the phase center of the array is set to the center element (Port 6), and then the array gain with the beam steering performance is observed by using the phase offset according to the steering angle. For example, when the steering angle is $15^{\circ}$, the array pattern is calculated using a phase difference of $47.5^{\circ}$ between the adjacent ports. In high-power jamming applications, it is important to measure the ARCs because all ports of the array antenna sensor are excited with a high power. The ARCs can be calculated based on the equation below [16-18]:

$$
\Gamma_{m}\left(\theta_{0}\right)=\frac{\sum_{n=1}^{N} S_{m n} e^{-j(n-1) k d \sin \theta_{0}}}{e^{-j(m-1) k d \sin \theta_{0}}}=\sum_{n=1}^{N} S_{m n} e^{-j(n-m) k d \sin \theta_{0}} .
$$

where $\Gamma_{m}$ is the ARC of the $m$ th port and $S_{m n}$ indicates an $N \times N$ scattering matrix at the $m$ th column and $n$th row. $N$ is the number of elements and $\theta_{0}$ is the steering angle. $k$ and $d$ are the wave number and array distance between the adjacent elements.

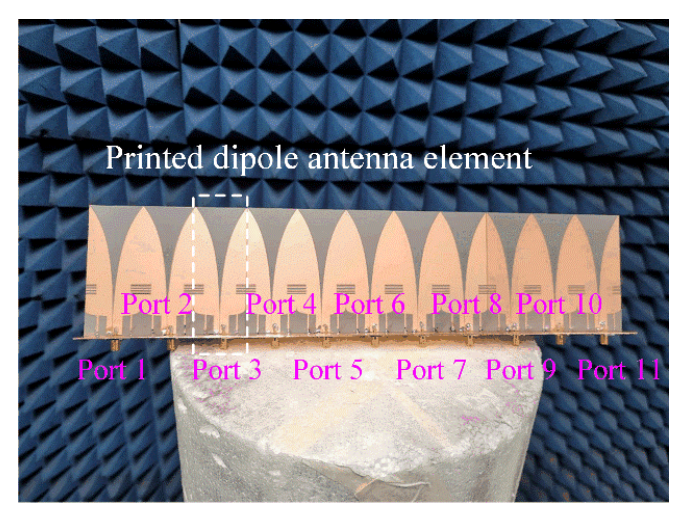

(a)

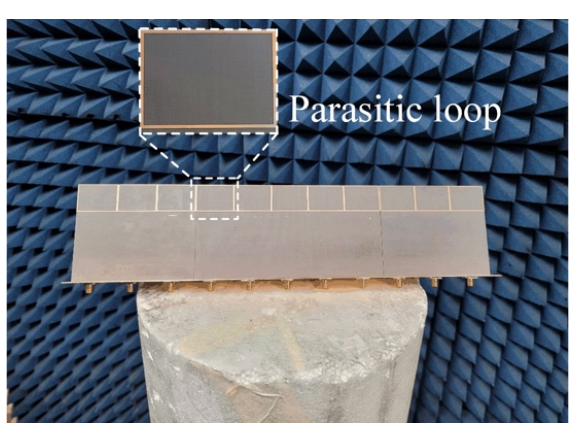

(b)

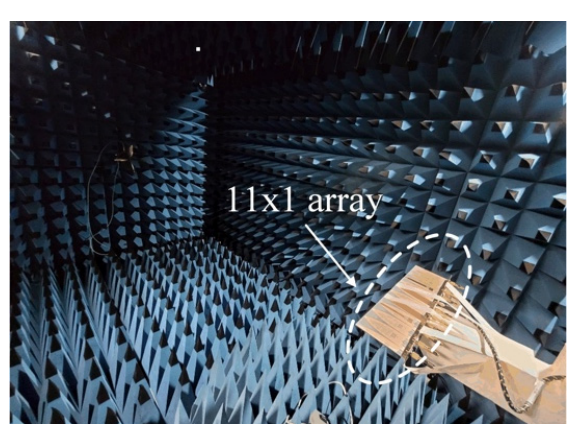

(c)

Figure 7. Photographs of the fabricated $11 \times 1$ uniform linear array antenna and measurement setup: (a) front view; (b) back view; (c) measurement setup. 
Table 2. Values of the optimized array antenna element.

\begin{tabular}{cccc}
\hline Parameter & Values & Parameter & Values \\
\hline$h_{1}$ & $96.3 \mathrm{~mm}$ & $l_{1}$ & $25.8 \mathrm{~mm}$ \\
$h_{2}$ & $14 \mathrm{~mm}$ & $l_{2}$ & $93.6 \mathrm{~mm}$ \\
$h_{3}$ & $29.9 \mathrm{~mm}$ & $d_{r}$ & $9.2 \mathrm{~mm}$ \\
$w_{1}$ & $38.2 \mathrm{~mm}$ & $d_{l}$ & $12 \mathrm{~mm}$ \\
$w_{2}$ & $0.9 \mathrm{~mm}$ & $c_{1}$ & -49.1 \\
$r_{i}$ & 0.038 & $c_{2}$ & -89.9 \\
$r_{0}$ & -0.9 & $c_{3}$ & $-4.5 \times 10^{6}$ \\
$s_{l}$ & $7.3 \mathrm{~mm}$ & $c_{4}$ & -15.3 \\
$s_{w}$ & $0.8 \mathrm{~mm}$ & $t$ & $1.6 \mathrm{~mm}$ \\
$s_{i}$ & $0.6 \mathrm{~mm}$ & $\left(f_{x}, f_{y}\right)$ & $(0,22.8)$ \\
$N$ & 5 & & \\
\hline
\end{tabular}

Figure 8 shows the comparisons of the simulated and measured ARCs according to the number of array elements. The solid, dashed, dotted, and dash-dotted lines indicate the simulations of the $3 \times 1,5 \times 1,11 \times 1$, and infinite uniform linear arrays, respectively. The dash-dotted-dotted line represents the measurement of the proposed $11 \times 1$ linear array antenna sensor. As the number of the array elements increased, the resulting ARCs decreased, especially in the high-end frequency band. Regarding the adjustment of the loop dimension for the periodic structure, the mutual coupling was decreased between the adjacent elements to enhance the ARCs. The average values of the simulated ARCs from 4.5 to $6 \mathrm{GHz}$ are $-11.5 \mathrm{~dB},-12.2 \mathrm{~dB},-13.4 \mathrm{~dB}$, and $-16.2 \mathrm{~dB}$ for the $3 \times 1,5 \times$ $1,11 \times 1$, and infinite linear arrays, respectively, while that of the measurement for the proposed array is $-14.7 \mathrm{~dB}$. Figure 9 shows the simulated and measured mutual couplings between the center element (Port 6) and the other elements. The measured and simulated average values of the mutual coupling results are $-49.3 \mathrm{~dB}$ and $-51 \mathrm{~dB}$. We examined the mutual couplings $\left(S_{2,1}, S_{3,1}, S_{4,1}, \ldots\right.$, and $\left.S_{10,1}\right)$ of the $11 \times 1$ array; the average value of the simulation was $-29.8 \mathrm{~dB}$. In addition, the beam steering performance, which is another essential array characteristic for high-power jamming applications, were investigated by measuring the active element patterns (AEPs) of the proposed array. To measure the AEPs, each array element was excited, while the other ports were terminated with $50 \Omega$ loads. Then, the AEPs for all ports were weighted and summed to calculate the steered array gains $[19,20]$. Herein, we assumed that the feeding network with the phase shifters was well designed with ideal characteristics. The array gain was calculated using the AEPs of all ports based on the following equation:

$$
P_{\text {array }}(\theta, \phi)=\frac{\sum_{n=1}^{N} \bar{w}_{n} \bar{v}_{n}(\theta, \phi)}{\sqrt{\sum_{n=1}^{N}\left|w_{n}\right|^{2}}},
$$

where $v_{n}$ is a complex vector of the AEP of an $n^{\text {th }}$ port and $w_{n}$ is a weighting vector for the beam steering.

Figure 10 shows the beam steering characteristics with steering angles, $\theta_{0}$, of $0^{\circ}$ and $15^{\circ}$ at $4 \mathrm{GHz}$ and $5 \mathrm{GHz}$. The solid and dashed lines indicate the measurements and simulations, and the blue and red lines denote the radiation patterns of the co- and crosspolarization. The measured and simulated results are well matched to each other. The measured bore-sight array gains of the co-polarization are $13.4 \mathrm{dBi}$ and $13.7 \mathrm{dBi}$ at $4 \mathrm{GHz}$ and $5 \mathrm{GHz}$, and those of the cross-polarizations are $-4.9 \mathrm{dBi}$ and $-3.4 \mathrm{dBi}$, respectively. When the beam is steered at the steering angle, $\theta_{0}$, of $15^{\circ}$, the maximum measured array gains of the co-polarization are $12.2 \mathrm{dBi}$ and $10.3 \mathrm{dBi}$ at $4 \mathrm{GHz}$ and $5 \mathrm{GHz}$, respectively. Moreover, the co-and cross-polarization level differences at the angle of the maximum gains are $14 \mathrm{~dB}$ at $4 \mathrm{GHz}$ and $11.4 \mathrm{~dB}$ at $5 \mathrm{GHz}$. Note that these beam steering results 
were calculated considering the ideal gain increment of the 11 elements from the bore-sight gains of $3.5 \mathrm{dBi}$ at $4 \mathrm{GHz}$ for the center array element. In addition, the measured back lobe levels seem to be higher than the simulated results because the extra obstacles, such as a RF cable and a positioner structure in the measurement setup, caused high back lobe levels. These results confirm that the proposed array antenna sensor can be applied to high-power jamming applications, as it is capable of achieving essential and required array performances. We also compared the antenna characteristics between the proposed array and the reference wideband arrays; the detailed explanations are listed in Table 3.

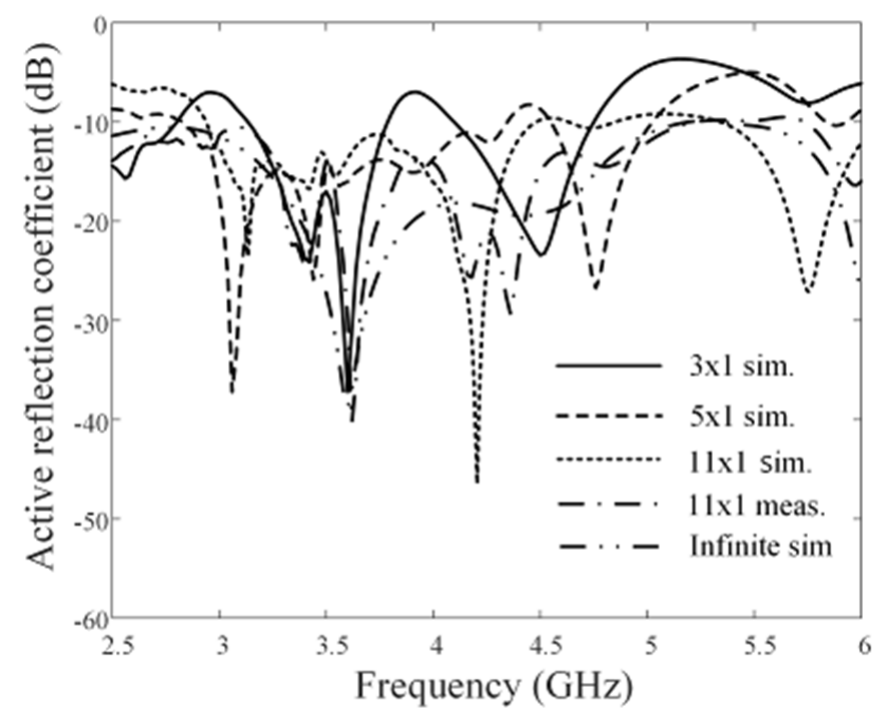

Figure 8. Comparisons of the simulated and measured ARCs according to the number of array elements.

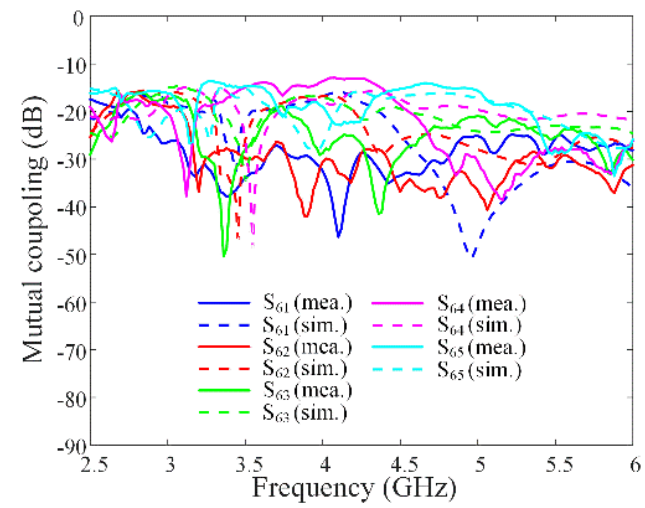

(a)

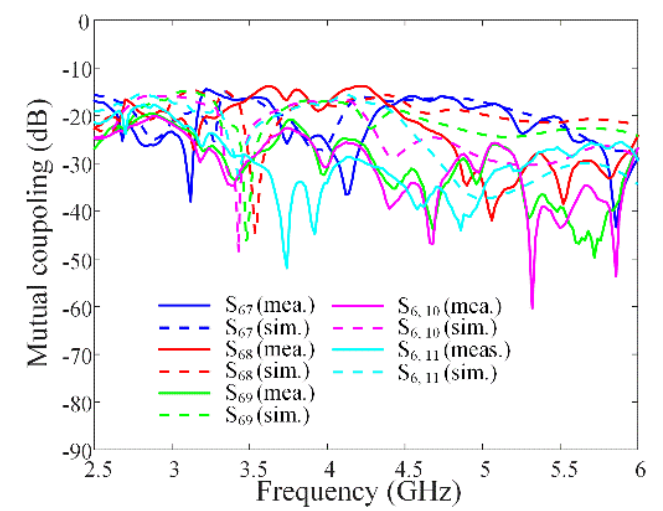

(b)

Figure 9. The measured and simulated mutual couplings: (a) the mutual couplings for port 1 to port 5; (b) the mutual couplings for port 7 to port 11. 


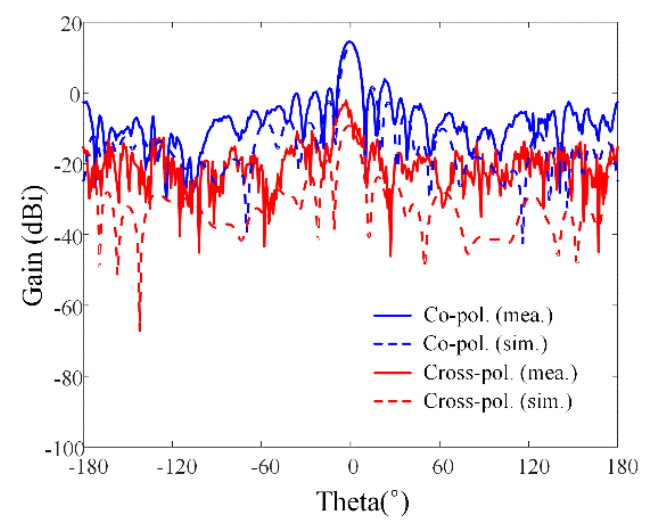

(a)

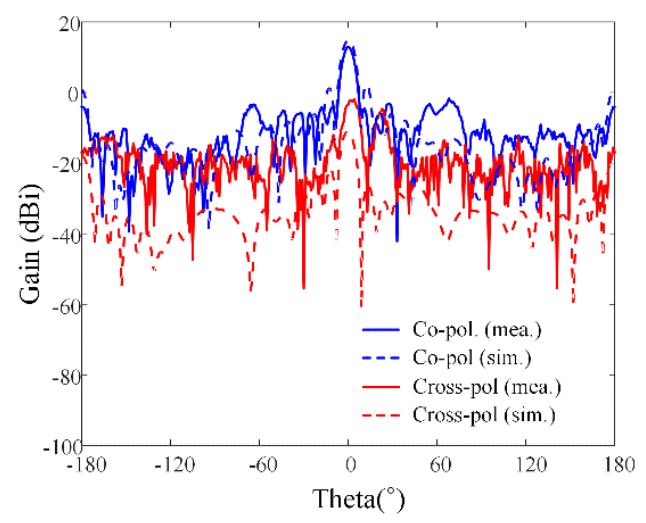

(c)

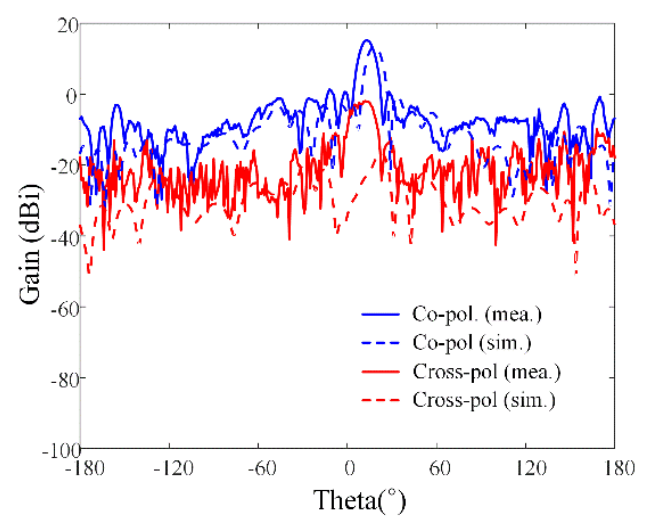

(b)

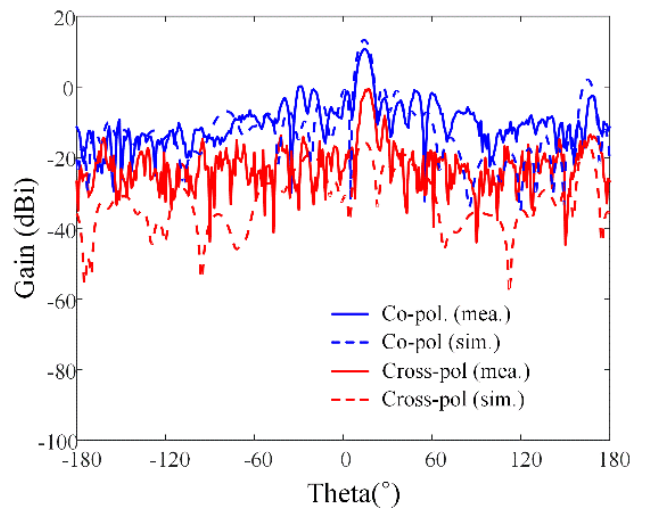

(d)

Figure 10. Array beam steering gains at $4 \mathrm{GHz}$ and $5 \mathrm{GHz}$ : (a) $\theta_{0}$ of $0^{\circ}$ at $4 \mathrm{GHz}$; (b) $\theta_{0}$ of $15^{\circ}$ at $4 \mathrm{GHz}$; (c) $\theta_{0}$ of $0^{\circ}$ at $5 \mathrm{GHz}$; (d) $\theta_{0}$ of $15^{\circ}$ at $5 \mathrm{GHz}$.

Table 3. Comparison of the wideband array.

\begin{tabular}{|c|c|c|c|c|c|}
\hline Reference & $\begin{array}{c}\text { Array Dimension } \\
\text { (Width mm } \times \text { Length } \\
\text { mm } \times \text { Thickness } \mathrm{mm})\end{array}$ & $\begin{array}{c}\text { Operating } \\
\text { Frequency Band } \\
\text { (GHz) }\end{array}$ & $\begin{array}{l}\text { The Number of } \\
\text { Elements }\end{array}$ & Substrate Material & $\begin{array}{l}\text { Array Gain } \\
\quad(\mathrm{dBi})\end{array}$ \\
\hline [9] & $500 \times 500 \times 1001.5$ & $1.75-3$ & 4 & Metal & $\begin{array}{c}19.7 \\
\text { (at } 2.45 \mathrm{GHz} \text { ) }\end{array}$ \\
\hline [12] & $480 \times 210$ & $2-4$ & 8 & Rogers RT5880 & $\begin{array}{c}\quad \geq 12 \\
\text { (at } 2 \text { to } 4 \mathrm{GHz} \text { ) }\end{array}$ \\
\hline [13] & $579.12 \times 579.12 \times 65.6$ & $0.3-2.15$ & 64 & TLY-5 & $\begin{array}{c}20 \\
\text { (at } 2 \mathrm{GHz})\end{array}$ \\
\hline [21] & $167.48 \times 158.25 \times 0.6$ & $\begin{array}{l}2.5-6.8 \\
\text { and } 7.5-9.5\end{array}$ & 6 & $\begin{array}{c}\text { Taconic } \\
\text { substrate } \\
\left(\varepsilon_{r}=4.3, \tan \delta=\right. \\
0.0035)\end{array}$ & $\begin{array}{c}14.12 \\
\text { (at } 4.5 \mathrm{GHz})\end{array}$ \\
\hline [22] & $43 \times 72 \times 0.762$ & $7-11.5$ & 4 & Rogers 3003 & $\begin{array}{c}12.1 \\
\text { (at } 10.7 \mathrm{GHz} \text { ) }\end{array}$ \\
\hline Proposed array & $420.2 \times 96.3 \times 1.6$ & $3-6$ & 11 & TLY-5 & $\begin{array}{c}13.7 \\
\text { (at } 4.5 \mathrm{GHz})\end{array}$ \\
\hline
\end{tabular}

\section{Conclusions}

The design of a novel wideband leaf-shaped printed dipole antenna sensor using a parasitic element was proposed to improve the impedance-matching bandwidth characteristics for high-power jamming applications. To obtain the desired wideband characteristics, the proposed antenna sensor was constructed of simple geometry elements: leaf-shaped 
dipole radiators, matching posts, rectangular slots, and a parasitic loop element. The leaf-shaped dipole radiators were designed with exponential curves and a TLY-5 substrate was employed to achieve high-power durability. The matching posts, rectangular slots, and parasitic elements were used to enhance the impedance matching characteristics. The measured average bore-sight gain and maximum reflection coefficient of the fabricated antenna sensor were $4.3 \mathrm{dBi}$ and $-10.1 \mathrm{~dB}$ in the frequency band from $3 \mathrm{GHz}$ to $6 \mathrm{GHz}$. In addition, the fractional bandwidth was $66.7 \%$ at the center frequency of $4.5 \mathrm{GHz}$. The proposed single antenna sensor was re-optimized using a periodic structure as an infinite array, and it was extended to a uniform linear array in order to confirm the array performances, such as the ARCs, AEPs, and beam steering gains. The fabricated $11 \times 1$ uniform array antenna sensor had an averaged ARC value of $-14.7 \mathrm{~dB}$ from 4.5 to $6 \mathrm{GHz}$, while the array gains of the co-polarization at the steering angles of $0^{\circ}$ and $15^{\circ}$ were $13.7 \mathrm{dBi}$ and $10.3 \mathrm{dBi}$ at $5 \mathrm{GHz}$.

Author Contributions: Conceptualization, E.K., T.H.L., S.P. and H.C.; methodology, E.K. and T.H.L.; software, E.K.; validation, E.K., T.H.L. and H.C.; formal analysis, E.K. and T.H.L.; investigation, E.K. and S.P.; writing —original draft preparation, E.K. and T.H.L.; writing—review and editing, E.K. and H.C.; visualization, E.K.; supervision, H.C.; project administration, H.C.; funding acquisition, H.C. All authors have read and agreed to the published version of the manuscript.

Funding: This work was supported by a grant-in-aid of HANWHA SYSTEMS.

Institutional Review Board Statement: Not applicable.

Informed Consent Statement: Not applicable.

Data Availability Statement: Not applicable.

Conflicts of Interest: The authors declare no conflict of interest.

\section{References}

1. Yoon, J.H.; Park, Y.; Roh, J.E.; Park, S.C. Multiple step interlaced beam scan to minimize the deviation of radar detection performance. J. Electromagn. Eng. Sci. 2020, 20, 125-130. [CrossRef]

2. Kindt, R.W.; Pickles, W.R. Ultrawideband all-metal flared-notch array radiator. IEEE Trans. Antennas Propag. 2010, 58, 3568-3575. [CrossRef]

3. Malekpoor, H.; Jam, S. Enhanced bandwidth of shorted patch antennas using folded-patch techniques. IEEE Antennas Wirel. Propag. Lett. 2013, 12, 198-201. [CrossRef]

4. Cai, Y.; Zhang, Y.; Qian, Z.; Cao, W.; Wang, L. Design of compact air-vias-perforated SIW horn antenna with partially detached broad walls. IEEE Antennas Wirel. Propag. Lett. 2016, 64, 2100-2107. [CrossRef]

5. Zhang, F; Fang, G.; Ji, Y.; Ju, H.; Shao, J. A novel compact double exponentially tapered slot antenna (DETSA) for GPR applications. IEEE Antennas Wirel. Propag. Lett. 2011, 10, 195-198. [CrossRef]

6. Holland, S.S.; Vouvakis, M.N. The planar ultrawideband modular antenna (PUMA) array. IEEE Trans. Antennas Propag. 2012, 60, 130-140. [CrossRef]

7. Anagnostou, D.E.; Papapolymerou, J.; Tentzeris, M.M.; Christodoulou, C.G. A printed log-periodic Koch-dipole array (LPKDA). IEEE Antennas Wirel. Propag. Lett. 2008, 7, 456-460. [CrossRef]

8. Lim, T.H.; Park, J.; Choo, H. Design of a Vivaldi-fed hybrid horn antenna for low-frequency gain enhancement. IEEE Trans. Antennas Propag. 2018, 66, 438-443. [CrossRef]

9. Choi, Y.S.; Hong, J.H.; Woo, J.M. Array synthesis horn antenna with an extended horn and a stepped corrugated structure for high-power microwave applications. J. Electromagn. Eng. Sci. 2020, 20, 110-114. [CrossRef]

10. Chang, L.; He, S.; Zhang, J.Q.; Li, D. A compact dielectric-loaded log-periodic dipole array (LPDA) antenna. IEEE Antennas Wirel. Propag. Lett. 2017, 16, 2759-2762. [CrossRef]

11. Holland, S.S.; Vouvakis, M.N. The banyan tree antenna array. IEEE Trans. Antennas Propag. 2011, 59, 4060-4070. [CrossRef]

12. Yang, Y.; Wang, Y.; Aly, F. Design of compact Vivaldi antenna arrays for UWB see through wall applications. Prog. Electromagn. Res. 2008, 82, 401-418. [CrossRef]

13. Zhang, H.; Yang, S.; Xiao, S.; Chen, Y.; Qu, S. Low-profile, lightweight, ultra-wideband tightly coupled dipole arrays loaded with split rings. IEEE Trans. Antennas Propag. 2019, 67, 4257-4262. [CrossRef]

14. Nikolaou, S.; Ponchak, G.E.; Papapolymerou, J.; Tentzeris, M.M. Conformal double exponentially tapered slot antenna (DETSA) on LCP for UWB applications. IEEE Trans. Antennas Propag. 2006, 54, 1663-1669. [CrossRef]

15. CST Microwave Studio. Available online: http://www.cst.com (accessed on 10 October 2021). 
16. Wasylkiwskyj, W.; Kahn, W. Element patterns and active reflection coefficient in uniform phased arrays. IEEE Trans. Antennas Propag. 1974, 22, 207-212. [CrossRef]

17. Pozar, D.M. The active element pattern. IEEE Trans. Antennas Propag. 1994, 42, 1176-1178. [CrossRef]

18. Hur, J.; Byun, G.; Choo, H. Design of a planar periodic lossy magnetic surface to improve active array patterns with enhanced isolation. IET Microw. Antennas Propag. 2018, 12, 2383-2389. [CrossRef]

19. Zhang, S.; Gong, S.; Gong, Q.; Guan, Y.; Lu, B. Application of the active element pattern method for calculation of the scattering pattern of large finite arrays. IEEE Trans. Antennas Propag. 2011, 10, 83-86. [CrossRef]

20. Kelley, D.F.; Stutzman, W.L. Array antenna pattern modeling methods that include mutual coupling effects. IEEE Trans. Antennas Propag. 1993, 41, 1625-1632. [CrossRef]

21. Ghimire, J.; Diba, F.D.; Kim, J.H.; Choi, D.Y. Vivaldi antenna arrays feed by frequency-independent phase Shifter for high directivity and gain used in microwave sensing and communication applications. Sensors 2021, 21, 6091. [CrossRef]

22. Wang, J.; Cui, W.; Zhou, Y.; Liu, R.; Wang, M.; Fan, C.; Li, E. Design of wideband antenna array with dielectric lens and defected ground structure. Electronics 2021, 10, 2066. [CrossRef] 